\title{
Prostate-Specific Antigen 5 Years following Stereotactic Body Radiation Therapy for Low- and Intermediate-Risk Prostate Cancer: An Ablative Procedure?
}

\author{
Shaan Kataria ${ }^{1}$, Harsha Koneru', Shan Guleria ${ }^{1}$, Malika Danner ${ }^{1}$, Marilyn Ayoob ${ }^{1}$, \\ Thomas Yung', Siyuan Lei', Brian T. Collins', Simeng Suy', John H. Lynch², \\ Thomas Kole ${ }^{3}$ and Sean P. Collins ${ }^{1 *}$
}

\begin{abstract}
'Department of Radiation Medicine, Georgetown University Hospital, Washington, DC, United States, ${ }^{2}$ Department of Urology, Georgetown University Hospital, Washington, DC, United States, ${ }^{3}$ Department of Radiation Oncology, Valley Hospital, Ridgewood, NJ, United States
\end{abstract}

OPEN ACCESS

Edited by:

Dwight E. Heron,

University of Pittsburgh Cancer Institute, United States

Reviewed by: Alan Jay Katz, Flushing Radiation Oncology, United States

Debra Freeman, Registry for Prostate Cancer Radiosurgery, United States

*Correspondence: Sean P. Collins spc9@georgetown.edu

Specialty section: This article was submitted to Radiation Oncology, a section of the journal

Frontiers in Oncology

Received: 20 March 2017 Accepted: 06 July 2017 Published: 24 July 2017

Citation:

Kataria S, Koneru H, Guleria S, Danner M, Ayoob M, Yung T, Lei S, Collins BT, Suy S, Lynch JH, Kole T and Collins SP (2017) Prostate-

Specific Antigen 5 Years following Stereotactic Body Radiation Therapy for Low- and Intermediate-Risk Prostate Cancer: An Ablative Procedure?

Front. Oncol. 7:157. doi: 10.3389/fonc.2017.00157
Background: Our previous work on early PSA kinetics following prostate stereotactic body radiation therapy (SBRT) demonstrated that an initial rapid and then slow PSA decline may result in very low PSA nadirs. This retrospective study sought to evaluate the PSA nadir 5 years following SBRT for low- and intermediate-risk prostate cancer (PCa).

Methods: 65 low- and 80 intermediate-risk PCa patients were treated definitively with SBRT to 35-37.5 Gy in 5 fractions at Georgetown University Hospital between January 2008 and October 2011. Patients who received androgen deprivation therapy were excluded from this study. Biochemical relapse was defined as a PSA rise $>2 \mathrm{ng} / \mathrm{ml}$ above the nadir and analyzed using the Kaplan-Meier method. The PSA nadir was defined as the lowest PSA value prior to biochemical relapse or as the lowest value recorded during follow-up. Prostate ablation was defined as a PSA nadir $<0.2 \mathrm{ng} / \mathrm{ml}$. Univariate logistic regression analysis was used to evaluate relevant variables on the likelihood of achieving a PSA nadir $<0.2 \mathrm{ng} / \mathrm{ml}$.

Results: The median age at the start of SBRT was 72 years. These patients had a median prostate volume of $36 \mathrm{cc}$ with a median $25 \%$ of total cores involved. At a median follow-up of 5.6 years, 86 and $37 \%$ of patients achieved a PSA nadir $\leq 0.5$ and $<0.2 \mathrm{ng} / \mathrm{ml}$, respectively. The median time to PSA nadir was 36 months. Two low and seven intermediate risk patients experienced a biochemical relapse. Regardless of the PSA outcome, the median PSA nadir for all patients was $0.2 \mathrm{ng} / \mathrm{ml}$. The 5-year biochemical relapse free survival (bRFS) rate for low- and intermediate-risk patients was 98.5 and $95 \%$, respectively. Initial PSA $(p=0.024)$ and a lower testosterone at the time of the PSA nadir $(p=0.049)$ were found to be significant predictors of achieving a PSA nadir $<0.2 \mathrm{ng} / \mathrm{ml}$.

Conclusion: SBRT for low- and intermediate-risk PCa is a convenient treatment option with low PSA nadirs and a high rate of early bRFS. Fewer than $40 \%$ of patients, however, achieved an ablative PSA nadir. Thus, the role of further dose escalation is an area of active investigation.

Keywords: stereotactic body radiation therapy, prostate cancer, PSA bounce, PSA recurrence, PSA kinetics, biochemical relapse, PSA, ablation 


\section{INTRODUCTION}

Men with prostate cancer ( $\mathrm{PCa}$ ) treated with prostatectomy generally achieve an undetectable PSA $(<0.1 \mathrm{ng} / \mathrm{ml})$ within weeks to months (1). A detectable PSA is highly associated with future clinical progression. Not all patients, however, will progress to local or distant disease recurrence because an elevated PSA may also be due to residual benign prostate tissue (2). For this reason, the American Urological Association defines biochemical recurrence as a PSA $\geq 0.2 \mathrm{ng} / \mathrm{ml}$ (3). The value of ultrasensitive PSA tests (sensitivity of $\leq 0.01 \mathrm{ng} / \mathrm{ml}$ ) in identifying early recurrences has yet to be shown $(4,5)$.

Conventionally fractionated external beam radiation therapy (EBRT) results in a slow PSA declines that then stabilizes. A PSA nadir to $<0.5 \mathrm{ng} / \mathrm{ml}$ predicts for lower rates of biochemical failure (Phoenix definition: $2 \mathrm{ng} / \mathrm{ml}$ above nadir) and distant failure (6). PSA nadirs to undetectable levels are uncommon because this technique does not fully ablate normal prostate tissue. Any subsequent PSA rises following the nadir may be due to benign PSA bounces, local recurrence or distant metastatic disease. Benign PSA bounces are generally small $(<1 \mathrm{ng} / \mathrm{ml})$ and transient, resolving over months to years (7).

Following brachytherapy, PSA nadirs are typically lower than conventionally fractionated EBRT with $90 \%$ of patients reaching a nadir of $<0.5 \mathrm{ng} / \mathrm{ml}$ at 5 years posttreatment and a median PSA of $0.1 \mathrm{ng} / \mathrm{ml}$ when measured with ultrasensitive PSA testing (8). In a study by Lo et al., if a patient's PSA was $\leq 0.4 \mathrm{ng} / \mathrm{ml}$ at 4 years post implantation, he had a $>99 \%$ chance of being free of disease at 8 years following treatment (9). The median PSA nadir for that study was $0.05 \mathrm{ng} / \mathrm{ml}$, suggesting that LDR brachytherapy performed in such a manner was potentially ablative. Patients with a 5-year PSA value of $<0.2 \mathrm{ng} / \mathrm{ml}$ have a $1-2 \%$ risk of developing biochemical failure within the next 5 years $(10,11)$.

Stereotactic body radiation therapy (SBRT) has emerged as a viable treatment option for many of the over 220,000 patients diagnosed with PCa in the United States each year (12). The American Society for Radiation Oncology defines SBRT as "an external beam radiation therapy method that very precisely delivers a high dose of radiation to an extracranial target" (13). Many terms have been used to describe SBRT including "stereotactic body ablative radiotherapy" and "extreme hypofractionation" $(14,15)$. In general, SBRT delivers $35-40$ Gy in 4-5 fractions, resulting in an overall lower PSA nadir compared to those treated with intensity modulated radiation therapy; these patients also exhibit a more rapid PSA decline in the second and third years post-SBRT (16-20). Dose escalation with SBRT has not been shown to improve biochemical relapse free survival (bRFS) in intermediate risk patients but may lead to worse toxicity $(21,22)$. This study sought to evaluate the PSA nadir 5 years following SBRT for PCa.

Abbreviations: ADT, androgen deprivation therapy; CT, computed tomography; CTV, clinical target volume; EQD2, equivalent dose in 2-Gy fractions; IMRT, intensity modulated radiation therapy; IRB, institutional review board; PTV, planning target volume; MR, magnetic resonance; SBRT, stereotactic body radiation therapy.

\section{MATERIALS AND METHODS}

\section{Patient Selection}

Patients eligible for study inclusion had histologically confirmed low- or intermediate-risk PCa treated with SBRT monotherapy per our institutional protocol and were followed for a minimum of 5 years. Patients who received androgen deprivation therapy were excluded from the study due to its known impact on the PSA nadir (23). Clinical stage was defined according to the seventh edition of the American Joint Committee on Cancer. Risk groups were defined using the D'Amico criteria. Approval from the MedStar Research Institute-Georgetown University Oncology Institutional Review Board (IRB) was obtained for retrospective review of data that were prospectively collected in our institutional database (IRB\#: 2009-510). The requirement to obtain written informed consent from research participants was waived by the Committee.

\section{SBRT Treatment Planning and Delivery}

Stereotactic body radiation therapy was delivered utilizing the CyberKnife roboticradiosurgical system (Accuray Inc., Sunnyvale, CA, USA). Required fiducial placement and computed tomography (CT)/magnetic resonance simulation procedures have been previously described (24). The clinical target volume (CTV) was defined as the prostatic capsule and proximal seminal vesicles identified on the pretreatment CT and/or MRI. The CTV to planning target volume (PTV) expansion was $5 \mathrm{~mm}$ in all directions except $3 \mathrm{~mm}$ posteriorly into the rectum. Fiducial-based tracking was utilized to account for interfraction and intrafraction prostate motion (25). Treatment planning and dose calculations were performed using Multiplan (Accuray Inc., Sunnyvale, CA, USA). Patients were treated to $35,36.25$, or 37.5 Gy delivered in 5 fractions to the PTV. Assuming an $\alpha / \beta$ ratio of 1.5 , this prescription corresponds to a tumor equivalent dose in 2-Gy fractions of approximately $85-90 \mathrm{~Gy}$. The prescription isodose line, however, was limited to $\geq 75 \%$ to restrict the maximum prostatic urethra dose to $133 \%$ of the prescription dose.

\section{Follow-up and Statistical Analysis}

Prostate-specific antigen and total testosterone levels were obtained prior to treatment and posttreatment every 3 months for the first year, every 6 months for the following 2 years, and yearly thereafter. Evaluated treatment response parameters included time to PSA nadir and the nadir value per individual patient. In addition to PSA kinetics, outcome measures studied included biochemical relapse as defined by the Phoenix definition (e.g., nadir $+2 \mathrm{ng} / \mathrm{ml}$ ) (23). In patients with a biochemical relapse, PSA nadir was defined as the lowest PSA prior to failure; in patients without a biochemical relapse, PSA nadir was defined as the lowest PSA recorded during follow-up. A benign PSA bounce was defined as a PSA rise of $0.2 \mathrm{ng} / \mathrm{ml}$ or greater that then returned to the previous PSA nadir or lower (7). Prostate ablation was defined as a PSA nadir $<0.2 \mathrm{ng} / \mathrm{ml}$ (2). Univariate logistic regression analysis was used to evaluate relevant variables on the likelihood of achieving a PSA nadir $<0.2 \mathrm{ng} / \mathrm{ml}$. 


\section{RESULTS}

From January 2008 to October 2011, 145 PCa patients were treated per our institutional SBRT monotherapy protocol (Table 1). By D’Amico classification, 65 patients were low risk, and 80 were intermediate risk. The median age at the start of SBRT was 72 years, and $40.7 \%$ of patients were non-Caucasian. The median prostate volume was $36 \mathrm{cc}$ with a median $25 \%$ of cores involved. $86.9 \%$ of the patients were treated with 36.25 Gy in five 7.25 Gy fractions.

At a median follow-up of 5.6 years (range 5-7.4 years), 84 and $37 \%$ of patients achieved a nadir $\leq 0.5$ and $<0.2 \mathrm{ng} / \mathrm{ml}$, respectively, and the median time to PSA nadir was 36 months.

TABLE 1 | Patient, tumor, and treatment characteristics.

$n=145$

\section{Age (years)}

Mean

Median (range)

Race

White

Black

Other

BMI

$18.5-24.9$

$25-29.9$

$\geq 30$

\begin{tabular}{|c|c|}
\hline \multicolumn{2}{|c|}{ Risk group (D'Amico) } \\
\hline Low & $65(44.8 \%)$ \\
\hline Intermediate & $80(55.2 \%)$ \\
\hline \multicolumn{2}{|c|}{ Clinical stage } \\
\hline T1c-T2a & $128(88.3 \%)$ \\
\hline $\mathrm{T} 2 \mathrm{~b}$ & $17(11.7 \%)$ \\
\hline \multicolumn{2}{|c|}{ Gleason score } \\
\hline$\leq 6$ & $74(51 \%)$ \\
\hline $7(3+4)$ & $49(33.8 \%)$ \\
\hline$(4+3)$ & $21(14.5 \%)$ \\
\hline \multicolumn{2}{|l|}{ PSA (ng/ml) } \\
\hline Mean & 6.54 \\
\hline Median & $5.70(1.8-18.6)$ \\
\hline \multicolumn{2}{|c|}{ Testosterone } \\
\hline Mean & 357.29 \\
\hline Median & $316(126-1,149)$ \\
\hline \multicolumn{2}{|c|}{ Prostate volume (cc) } \\
\hline Mean & 39.19 \\
\hline Median & 36.05 (11.56-138.69) \\
\hline \multicolumn{2}{|c|}{ \# of Cores involved } \\
\hline Mean & 3 \\
\hline Median & $3(1-10)$ \\
\hline \multicolumn{2}{|c|}{$\%$ of Total cores positive } \\
\hline Mean & 30.2 \\
\hline Median & $25(3-100)$ \\
\hline \multicolumn{2}{|c|}{ Maximum $\%$ of a single involved core } \\
\hline Mean & 37.79 \\
\hline Median & $30(2-95)$ \\
\hline \multicolumn{2}{|c|}{ Treatment dose (Gy) } \\
\hline 35 & 15 (10.3\%) \\
\hline 36.25 & 126 (86.9\%) \\
\hline 37.5 & 74 (2.8\%) \\
\hline
\end{tabular}

There were nine biochemical relapses, occurring in two low risk and seven intermediate-risk patients; the median time to relapse was 4.1 years. Regardless of the PSA outcome, the median PSA nadir for all patients was $0.2 \mathrm{ng} / \mathrm{ml}$ (Table 2). Benign PSA bounces were identified in 58 patients (40\%), and four patients experienced a PSA bounce of greater than $2 \mathrm{ng} / \mathrm{ml}$. The percentage of patients without a biochemical relapse reaching a given PSA nadir during follow-up is described in Table 3. There was little difference between the pretreatment testosterone level and the testosterone level measured at the PSA nadir.

At 5 years posttreatment, the median pretreatment PSA of $5.7 \mathrm{ng} / \mathrm{ml}$ (range, $1.8-18.6 \mathrm{ng} / \mathrm{ml}$ ) declined to a median of $0.3 \mathrm{ng} / \mathrm{ml}$ (range, $0-53 \mathrm{ng} / \mathrm{ml}$ ). There was no statistically significant difference between the 5-year bRFS rate for low- $(98.5 \%)$ and intermediate-risk (95.5\%) patients (Figure 1). The distribution of PSA values at 5 years in patients without biochemical relapse is illustrated in Figure 2.

A PSA nadir of $<0.2 \mathrm{ng} / \mathrm{ml}$ was selected to estimate the likelihood of achieving long-term bRFS. Specific clinical features such as age, prostate volume, T-stage, Gleason score, baseline PSA, pretreatment testosterone, testosterone at the time of PSA nadir, time to PSA nadir, and the percentage of cores involved were evaluated as predictors for achieving a PSA $<0.2 \mathrm{ng} / \mathrm{ml}$. Utilizing univariate logistic regression analysis, only a lower baseline PSA and a lower testosterone level at the time of the PSA nadir were found to be significant predictors of achieving a PSA $<0.2 \mathrm{ng} / \mathrm{ml}$ (Table 4).

\section{DISCUSSION}

Conventionally fractionated EBRT is designed to safely eradicate cancerous cells while minimizing the dose to surrounding normal tissues and reducing the risk of unnecessary toxicity. Utilization of this technique, however, may not be adequate to eradicate all cancer cells with the most common site of recurrence being

TABLE 2 | PSA outcomes at a median follow-up of 5.6 years.

\begin{tabular}{lc}
\hline & All $(\boldsymbol{n}=\mathbf{1 4 5})$ \\
\hline \# of Biochemical failures & 9 \\
Median months to biochemical failure & $50(34-81)$ \\
Median PSA nadir (ng/ml) & $0.2(0.02-2.1)$ \\
Median months to nadir & $36(3-84)$ \\
PSA nadir $\leq 0.5$ & $122(84 \%)$ \\
PSA nadir <0.2 & $54(37 \%)$ \\
Median testosterone at PSA nadir & $305(73-1,423)$
\end{tabular}

TABLE 3 | The percentage of patients with biochemical RFS reaching a given PSA in the years following stereotactic body radiation therapy.

\begin{tabular}{lcrrrr}
\hline PSA (ng/ml) & $\mathbf{1}$ (year) & $\mathbf{2}$ & $\mathbf{3}$ & $\mathbf{4}$ & $\mathbf{5}$ \\
\hline$\leq 1$ & $61 \%$ & $90 \%$ & $95 \%$ & $96 \%$ & $93 \%$ \\
$\leq 0.5$ & $27 \%$ & $63 \%$ & $72 \%$ & $75 \%$ & $73 \%$ \\
$\leq 0.2$ & $6 \%$ & $20 \%$ & $37 \%$ & $43 \%$ & $45 \%$ \\
$\leq 0.1$ & $2 \%$ & $7 \%$ & $17 \%$ & $24 \%$ & $23 \%$ \\
$<0.1$ & $0 \%$ & $0 \%$ & $0 \%$ & $1 \%$ & $7 \%$ \\
$N$ & 125 & 126 & 130 & 121 & 128
\end{tabular}




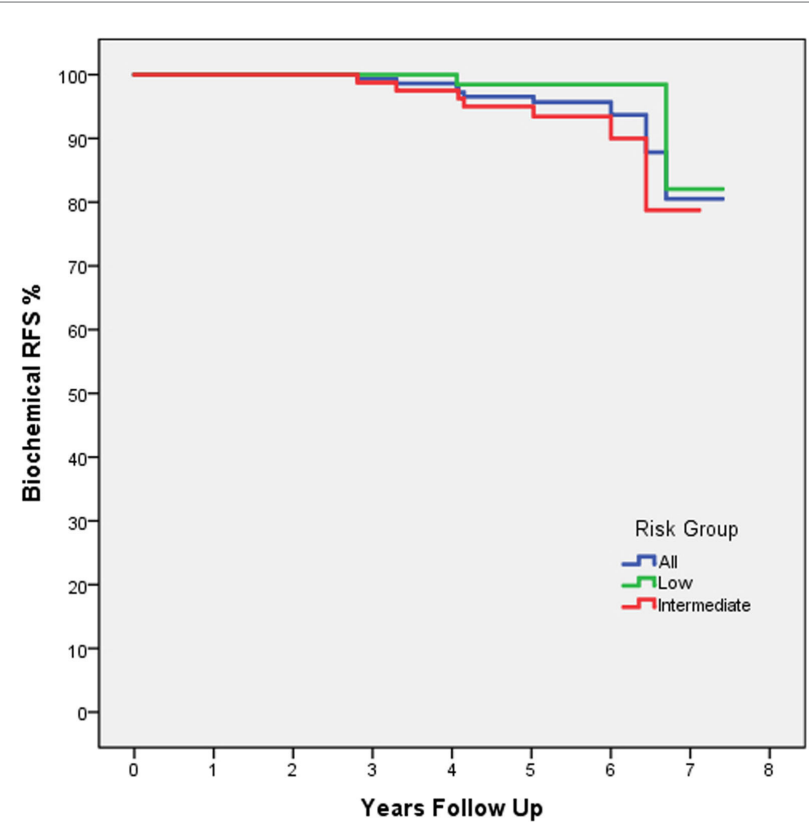

FIGURE 1 | Biochemical RFS by D'Amico risk group: all patients (blue), low risk (green), and intermediate risk (red). The dashed line indicates the 5-year follow-up time point.

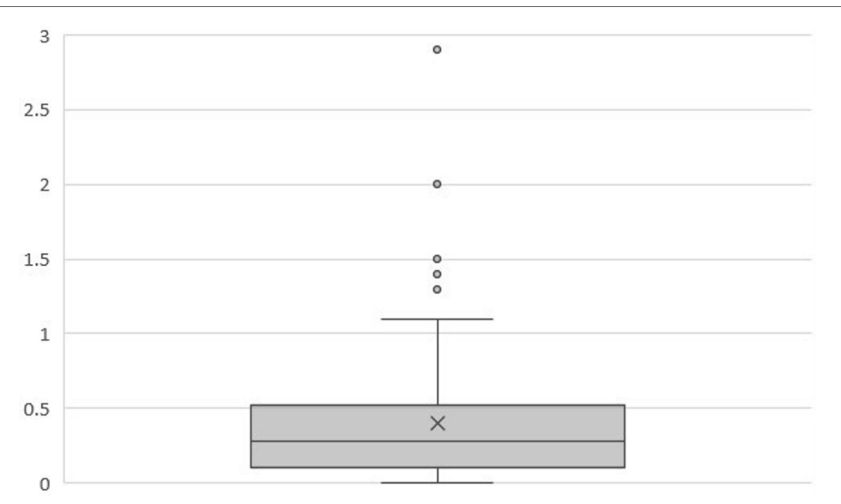

FIGURE 2 | Box plot illustrating the distribution of PSA values $(\mathrm{ng} / \mathrm{ml})$ at 5 years in patients without biochemical relapse $(n=128)$. Mean $=0.40$. Median $=0.28$. $Q 1=0.1 . Q 3=0.52$.

within the prostate (26). Ablation is the destruction of cancerous cells and/or normal tissue by large radiation doses via vascular mediated necrosis (27). Unfortunately, delivering SBRT with ablative doses of radiation to the entire prostate ( $>40 \mathrm{~Gy}$ ) have led to high rates of $>$ Grade 3 toxicity (21). Doses of 35-40 Gy in 4-5 fractions have been found to be safe while achieving PSA nadirs lower than conventionally fractionated $\operatorname{EBRT}(17,28)$. It remains unclear if these doses are adequate for long-term ( $>20$ years) local control.

Recently published data indicate that fewer than $20 \%$ of low risk PCa patients under the age of 65 years at diagnosis are treated with conventionally fractionated EBRT, while nearly $50 \%$ of patients are treated with radical prostatectomy (29). This
TABLE 4 | Univariate logistic regression.

\begin{tabular}{|c|c|c|c|}
\hline \multicolumn{4}{|c|}{ Univariate logistic regression } \\
\hline Variable & OR & $95 \% \mathrm{Cl}$ & $p$-Value \\
\hline Age (years) & 0.997 & $(0.948-1.049)$ & 0.906 \\
\hline Prostate volume $\left(\mathrm{cm}^{3}\right)$ & 0.981 & $(0.959-1.004)$ & 0.1 \\
\hline \multicolumn{4}{|l|}{ T-stage } \\
\hline T1c-T2a & 1 & & \\
\hline $\mathrm{T} 2 \mathrm{~b}-\mathrm{T} 2 \mathrm{c}$ & 1.137 & $(0.306-2.530)$ & 0.812 \\
\hline \multicolumn{4}{|l|}{ Gleason score } \\
\hline \multicolumn{4}{|l|}{$\leq 6$} \\
\hline 7 & 1.134 & $(0.579-2.218)$ & 0.714 \\
\hline PSA, baseline (ng/ml) & 0.856 & $(0.748-0.980)$ & 0.024 \\
\hline Testosterone, baseline (ng/dl) & 1 & (0.998-1.002) & 0.862 \\
\hline Testosterone, nadir (ng/dl) & 0.997 & $(0.993-1.000)$ & 0.049 \\
\hline Time to PSA nadir (months) & 1.014 & $(0.997-1.033)$ & 0.116 \\
\hline$\%$ Positive cores involved & 1.013 & $(0.997-1.029)$ & 0.11 \\
\hline
\end{tabular}

Predictors of achieving a PSA nadir $<0.2 \mathrm{ng} / \mathrm{ml}$.

$p$ values in bold are statistically significant.

trend may be due to the fact that many physicians believe that young men with PCa are at a higher risk of treatment failure following primary conventionally fractionated EBRT due to their predicted long life expectancy and the non-ablative nature of this radiotherapy technique (30). Not all men are ideal candidates for surgery and conventionally fractionated EBRT requires $>8$ weeks of daily treatment. Furthermore, both prostatectomy and conventionally fractionated EBRT result in similar long-term declines in functional outcomes (31).

Brachytherapy is a well-established alternative to surgery for these men due to the achievement of very low PSA nadirs when administered following strict guidelines (32). Patients treated with low-dose brachytherapy with a biologic effective dose (BED) $>180$ Gy resulted in 10-year freedom from PSA failure rates of $>90 \%$ (33). Not all patients, however, are ideal candidates for brachytherapy (i.e., large prostate, prior TURP or high IPSS) (34) and are looking for a convenient alternative. SBRT delivered to $35-37.25$ Gy in 5 fractions provides a BED of $>198$ Gy resulting in greater coverage of the CTV and a more conformal and homogeneic dose distribution compared to brachytherapy. Our 5-year bRFS for low- (98.5\%) and intermediate-risk (95.5\%) patients are comparable to those reported for high dose conventionally fractionated radiation therapy and low-dose brachytherapy (35-37). Further follow-up of PCa patients treated with SBRT will be required to confirm long-term cancer control suggested by its low PSA nadir.

This study has several identifiable limitations. First, PSAs may continue to decline for years after prostate radiotherapy, and 5 years of follow-up may be inadequate to assess the ultimate PSA nadir for an individual patient. Second, the PSA nadir might not be an ideal indicator of long-term cancer control due to its dependence on the pretreatment PSA and the testosterone level at the time of PSA nadir. Finally, most patients were followed utilizing standard PSA tests with a sensitivity of $0.1 \mathrm{ng} / \mathrm{ml}$. A standard approach was not utilized when ultrasensitive PSA tests were performed that resulted in values $<0.1 \mathrm{ng} / \mathrm{ml}$. When the ultrasensitive test was employed, however, several patients achieved nadirs as low as $0.05 \mathrm{ng} / \mathrm{ml}$. Therefore, it is likely that 
the mean PSA nadir would have been lower if the ultrasensitive tests were routinely employed.

\section{CONCLUSION}

Stereotactic body radiation therapy for clinically localized lowand intermediate-risk PCa is a convenient treatment option with low PSA nadirs suggestive of high rates of early bRFS. In this study, although fewer than $40 \%$ of patients achieved an ablative PSA nadir, high rates of bRFS have been observed. Further follow-up of PCa patients treated with SBRT monotherapy is

\section{REFERENCES}

1. Furusato B, Rosner IL, Osborn D, Ali A, Srivastava S, Davis CJ, et al. Do patients with low volume prostate cancer have prostate specific antigen recurrence following radical prostatectomy? J Clin Pathol (2008) 61:1038-40. doi:10.1136/jcp.2008.057794

2. Stephenson AJ, Kattan MW, Eastham JA, Dotan ZA, Bianco FJ Jr, Lilja H, et al. Defining biochemical recurrence of prostate cancer after radical prostatectomy: a proposal for a standardized definition. J Clin Oncol (2006) 24:3973. doi:10.1200/JCO.2005.04.0756

3. Cookson MS, Aus G, Burnett AL, Canby-Hagino ED, D'Amico AV, Dmochowski RR, et al. Variation in the definition of biochemical recurrence in patients treated for localized prostate cancer: the American Urological Association prostate guidelines for localized prostate cancer update panel report and recommendations for a standard in the reporting of surgical outcomes. J Urol (2007) 177:540-5. doi:10.1016/j.juro.2006.10.097

4. Shen S, Lepor H, Yaffee R, Taneja SS. Ultrasensitive serum prostate specific antigen nadir accurately predicts the risk of early relapse after radical prostatectomy. J Urol (2005) 173:777-80. doi:10.1097/01. ju.0000153619.33446.60

5. Taylor JA, Koff SG, Dauser DA, McLeod DG. The relationship of ultrasensitive measurements of prostate-specific antigen levels to prostate cancer recurrence after radical prostatectomy. BJU Int (2006) 98:540. doi:10.1111/j.1464-410X.2006.06294.x

6. Ray ME, Thames HD, Levy LB, Horwitz EM, Kupelian PA, Martinez AA, et al. PSA nadir predicts biochemical and distant failures after external beam radiotherapy for prostate cancer: a multi-institutional analysis. Int J Radiat Oncol Biol Phys (2006) 64(4):1140-50. doi:10.1016/j.ijrobp.2005.07.006

7. Ciezki JP, Reddy CA, Garcia J, Angermeier K, Ulchaker J, Mahadevan A, et al. PSA kinetics after prostate brachytherapy: PSA bounce phenomenon and its implications for PSA doubling time. Int J Radiat Oncol Biol Phys (2006) 64:512-7. doi:10.1016/j.ijrobp.2005.07.960

8. Zelefsky MJ. PSA bounce versus biochemical failure following prostate brachytherapy. Nat Clin Pract Urol (2006) 3(11):578-9. doi:10.1038/ ncpuro0611

9. Lo AC, Morris WJ, Lapointe V, Hamm J, Keyes M, Pickles T, et al. Prostatespecific antigen at 4 to 5 years after low-dose-rate prostate brachytherapy is a strong predictor of disease-free survival. Int J Radiat Oncol Biol Phys (2014) 88(1):87-93. doi:10.1016/j.ijrobp.2013.10.010

10. Critz FA. Time to achieve a prostate specific antigen nadir of $0.2 \mathrm{ng} / \mathrm{ml}$. after simultaneous irradiation for prostate cancer. J Urol (2002) 168(6):2434-8. doi:10.1097/00005392-200212000-00020

11. Stock RG, Klein TJ, Cesaretti JA, Stone NN. Prognostic significance of 5-year PSA value for predicting prostate cancer recurrence after brachytherapy alone and combined with hormonal therapy and/or external beam radiotherapy. Int J Radiat Oncol Biol Phys (2009) 74(3):753-8. doi:10.1016/j. ijrobp.2008.08.049

12. Baker BR, Basak R, Mohiuddin JJ, Chen RC. Use of stereotactic body radiotherapy for prostate cancer in the United States from 2004 through 2012. Cancer (2016) 122(14):2234-41. doi:10.1002/cncr.30034

13. Potters L, Kavanagh B, Galvin JM, Hevezi JM, Janjan NA, Larson DA, et al. American Society for Therapeutic Radiology and Oncology (ASTRO) and American College of Radiology (ACR) practice guideline for the performance required to determine the long-term outcomes of this technique. The role of further dose escalation is an area of active investigation.

\section{AUTHOR CONTRIBUTIONS}

SK, HK, SG, SS, and TK contributed in data collection and analysis. MD contributed as a research coordinator. SL, MA, TY, BC, $\mathrm{JL}, \mathrm{TK}$, and SC contributed in treatment planning, the delivery of stereotactic body radiation therapy, and in patient care pre- and posttreatment.

of stereotactic body radiation therapy. Int J Radiat Oncol Biol Phys (2010) 76(2):326-32. doi:10.1016/j.ijrobp.2009.09.042

14. Cabrera AR, Lee WR. Hypofractionation for clinically localized prostate cancer. Semin Radiat Oncol (2013) 23(3):191-7. doi:10.1016/j.semradonc 2013.01.005

15. Loblaw A, Cheung P, D'Alimonte L, Deabreu A, Mamedov A, Zhang L, et al. Prostate stereotactic ablative body radiotherapy using a standard linear accelerator: toxicity, biochemical, and pathological outcomes. Radiother Oncol (2013) 107(2):153-8. doi:10.1016/j.radonc.2013.03.022

16. Katz AJ, Santoro M, Diblasio F, Ashley R. Stereotactic body radiotherapy for localized prostate cancer: disease control and quality of life at 6 years. Radiat Oncol (2013) 8:118. doi:10.1186/1748-717X-8-118

17. Mantz C. A phase II trial of stereotactic ablative body radiotherapy for low-risk prostate cancer using a non-robotic linear accelerator and real-time target tracking: report of toxicity, quality of life, and disease control outcomes with 5-year minimum follow-up. Front Oncol (2014) 4:279. doi:10.3389/ fonc.2014.00279

18. Kim DN, Straka C, Cho LC, Lotan Y, Yan J, Kavanagh B, et al. Early and multiple PSA bounces can occur following high-dose prostate stereotactic body radiation therapy: subset analysis of a phase $1 / 2$ trial. Pract Radiat Oncol (2017) 7(1):e43-9. doi:10.1016/j.prro.2016.06.010

19. Kole TP, Chen LN, Obayomi-Davies O, Kim JS, Lei S, Suy S, et al. Prostate specific antigen kinetics following robotic stereotactic body radiotherapy for localized prostate cancer. Acta Oncol (2015) 54(6):832-8. doi:10.3109/02841 86X.2014.983656

20. Anwar M, Weinberg V, Chang AJ, Hsu IC, Roach M III, Gottschalk A. Hypofractionated SBRT versus conventionally fractionated EBRT for prostate cancer: comparison of PSA slope and nadir. Radiat Oncol (2014) 9:42. doi:10.1186/1748-717X-9-42

21. Hegde JV, Collins SP, Fuller DB, King CR, Demanes DJ, Wang PC, et al. A pooled analysis of biochemical failure in intermediate-risk prostate cancer following definitive stereotactic body radiotherapy (SBRT) or high-dose-rate brachytherapy (HDR-B) monotherapy. Am J Clin Oncol (2016). doi:10.1097/ COC.0000000000000311

22. Kim DW, Cho LC, Straka C, Christie A, Lotan Y, Pistenmaa D, et al. Predictor of rectal tolerance observed in a dose-escalated phase 1-2 trial of stereotactic body radiation therapy for prostate cancer. Int J Radiat Oncol Biol Phys (2014) 89(3):509-17. doi:10.1016/j.ijrobp.2014.03.012

23. Roach M III, Hanks G, Thames H Jr, Schellhammer P, Shipley WU, Sokol GH, et al. Defining biochemical failure following radiotherapy with or without hormonal therapy in men with clinically localized prostate cancer: recommendations of the RTOG-ASTRO Phoenix Consensus Conference. Int J Radiat Oncol Biol Phys (2006) 65(4):965-74. doi:10.1016/j.ijrobp.2006.04.029

24. Lei S, Piel N, Oermann EK, Chen V, Ju AW, Dahal KN, et al. Six-dimensional correction of intra-fractional prostate motion with CyberKnife stereotactic body radiation therapy. Front Oncol (2011) 1:48. doi:10.3389/fonc.2011.00048

25. Xie Y, Djajaputra D, King CR, Hossain S, Ma L, Xing L. Intrafractional motion of the prostate during hypofractionated radiotherapy. Int J Radiat Oncol Biol Phys (2008) 72:236-46. doi:10.1016/j.ijrobp.2008.04.051

26. Zumsteg ZS, Spratt DE, Romesser PB, Pei X, Zhang Z, Kollmeier M, et al. Anatomical patterns of recurrence following biochemical relapse in the dose escalation era of external beam radiotherapy for prostate cancer. J Urol (2015) 194(6):1624-30. doi:10.1016/j.juro.2015.06.100 
27. Brown JM, Koong AC. High-dose single-fraction radiotherapy: exploiting a new biology? Int J Radiat Oncol Biol Phys (2008) 71(2):324-5. doi:10.1016/j. ijrobp.2008.02.003

28. Kishan AU, Wang PC, Upadhyaya SK, Hauswald H, Demanes DJ, Nickols NG, et al. SBRT and HDR brachytherapy produce lower PSA nadirs and different PSA decay patterns than conventionally fractionated IMRT in patients with low- or intermediate-risk prostate cancer. Pract Radiat Oncol (2016) 6(4):268-75. doi:10.1016/j.prro.2015.11.002

29. Gray PJ, Lin CC, Cooperberg MR, Jemal A, Efstathiou JA. Temporal trends and the impact of race, insurance, and socioeconomic status in the management of localized prostate cancer. Eur Urol (2017) 71(5):729-37. doi:10.1016/j. eururo.2016.08.047

30. Klayton TL, Ruth K, Horwitz EM, Uzzo RG, Kutikov A, Chen DY, et al. Young age under 60 years is not a contraindication to treatment with definitive dose escalated radiotherapy for prostate cancer. Radiother Oncol (2011) 101(3):508-12. doi:10.1016/j.radonc.2011.07.022

31. Resnick MJ, Koyama T, Fan KH, Albertsen PC, Goodman M, Hamilton AS, et al. Long-term functional outcomes after treatment for localized prostate cancer. N Engl J Med (2013) 368(5):436-45. doi:10.1056/NEJMoa1209978

32. Burri RJ, Ho AY, Forsythe K, Cesaretti JA, Stone NN, Stock RG. Young men have equivalent biochemical outcomes compared with older men after treatment with brachytherapy for prostate cancer. Int J Radiat Oncol Biol Phys (2010) 77(5):1315-21. doi:10.1016/j.ijrobp.2009.06.052

33. Stock RG, Stone NN, Cesaretti JA, Rosenstein BS. Biologically effective dose values for prostate brachytherapy: effects on PSA failure and posttreatment biopsy results. Int J Radiat Oncol Biol Phys (2006) 64(2):527-33. doi:10.1016/j. ijrobp.2005.07.981

34. Davis BJ,HorwitzEM,LeeWR, CrookJM,StockRG, MerrickGS, etal. American Brachytherapy Society consensus guidelines for transrectal ultrasound-guided permanent prostate brachytherapy. Brachytherapy (2012) 11(1):6-19. doi:10.1016/j.brachy.2011.07.005

35. Bryant C, Smith TL, Henderson RH, Hoppe BS, Mendenhall WM, Nichols RC, et al. Five-year biochemical results, toxicity, and patientreported quality of life after delivery of dose-escalated image guided proton therapy for prostate cancer. Int J Radiat Oncol Biol Phys (2016) 95(1):422-34. doi:10.1016/j.ijrobp.2016.02.038

36. Fellin G, Mirri MA, Santoro L, Jereczek-Fossa BA, Divan C, Mussari S, et al Low dose rate brachytherapy (LDR-BT) as monotherapy for early stage prostate cancer in Italy: practice and outcome analysis in a series of 2237 patients from 11 institutions. Br J Radiol (2016) 89(1065):20150981. doi:10.1259/ bjr.20150981

37. Rasmusson E, Gunnlaugsson A, Kjellén E, Nilsson P, Einarsdottir M, Wieslander E, et al. Low-dose rate brachytherapy with I-125 seeds has an excellent 5-year outcome with few side effects in patients with low-risk prostate cancer. Acta Oncol (2016) 55(8):1016-21. doi:10.1080/0284186X.2016.1175659

Conflict of Interest Statement: SC and BC serve as clinical consultants to Accuray Inc. The Department of Radiation Medicine at Georgetown University Hospital receives a grant from Accuray to support a research coordinator. The other authors declare that they have no competing interests.

Copyright (c) 2017 Kataria, Koneru, Guleria, Danner, Ayoob, Yung, Lei, Collins, Suy, Lynch, Kole and Collins. This is an open-access article distributed under the terms of the Creative Commons Attribution License (CC BY). The use, distribution or reproduction in other forums is permitted, provided the original author(s) or licensor are credited and that the original publication in this journal is cited, in accordance with accepted academic practice. No use, distribution or reproduction is permitted which does not comply with these terms. 